\title{
Separation and Determination of Carnitine and Its Esters in Human Serum
}

\author{
Masaru Maebashi, Norimitsu Kawamura, Mitsuo Sato, \\ Kaoru Yoshinaga and Masashige Suzuki* \\ The Second Department of Internal Medicine, Tohoku University \\ School of Medicine, Sendai and Laboratory of Nutrition,* \\ Department of Health Science, Tokyo University of Education, \\ Tokyo
}

\begin{abstract}
Maebashi, M., Kawamura, N., Sato, M., Yoshinaga, K. and Suzuki, M. Separation and Determination of Carnitine and Its Esters in Human Serum. Tohoku J. exp. Med., 1975, $116(2)$, 203-204_A colorimetric method for the determination of carnitine and its derivatives is described. Free carnitine, acetylcarnitine and palmitoylcarnitine were extracted with chloroform-methanol. After evaporation, the residue was dissolved in $n$-butanol and water; palmitoylcarnitine in the organic phase, and free carnitine and acetylcarnitine in the aqueous phase. Acetylcarnitine was separated from free carnitine by passing the aqueous phase through a column of Amberlite CG-120 $\left(\mathrm{H}^{+}\right)$. Separated carnitine derivatives were hydrolyzed to free carnitine which was followed by the Amberlite column chromatography. After eluting with $2 \mathrm{~N} \mathrm{NH}_{4} \mathrm{OH}$ solution, the samples were esterified and determined colorimetrically. _ carnitine; acetylcarnitine; palmitoylcarnitine
\end{abstract}

For the separation and determination of carnitine and its esters in biological materials, several procedures have been employed (Marquis and Fritz 1965; Mehlman and Therriault 1965; Lindstedt and Lindstedt 1965; Bøhmer et al. 1966; Gumpen and Norum 1973). It is still desirable, however, to develop more simple and reliable methods for this purpose. In the previous studies (Maebashi et al. 1974), a column of anion exchanger Amberlite $\mathrm{CG}-120\left(\mathrm{H}^{+}\right)$resin was found to give a satisfactory separation of carnitine in urine and to make the investigation easier. A combination of hydrolysis of carnitine esters and column chromatography seems to fulfill the above requirements, as demonstrated in the present study.

Test samples were prepared in a system containing L-carnitine chloride, L-palmitoylcarmitine and L-acetylcarnitine in a range of $0.5-10 \mu$ moles. To these samples equal volume of $n$-butanol was added. After shaking vigorously for $10 \mathrm{~min}$, the mixtures were divided into two phases; butanol phase and water phase. Palmitoylcarnitine was recovered in the butanol phase, and free carnitine and acetylcarnitine were in the water phase. The water phase was applied to an Amberlite $\mathrm{CG}-120\left(\mathrm{H}^{+}\right)$column, $0.5 \mathrm{~cm}$ in diameter, the resin bed $5 \mathrm{~cm}$ high. After application, free carnitine was eluted out with $20 \mathrm{ml}$ of $2 \mathrm{~N} \mathrm{NH}_{4} \mathrm{OH}$ solution. Acetylcarnitine, passed through the column with water, was evaporated under reduced pressure to dryness and the residue was dissolved in $1 \mathrm{ml}$ of $6 \mathrm{~N}$ methanolic $\mathrm{HCl}$. This solution was heated in a sealed ampule at $100^{\circ} \mathrm{C}$ for $6 \mathrm{hr}$ to complete the hydrolysis of acetylcarnitine. Then the solvent was removed by evaporation and residual acid was eliminated in a vacuum desiccator containing $\mathrm{KOH}$. To the residue were added $5 \mathrm{ml}$ of $n$-butanol and $5 \mathrm{ml}$ of distilled water. After shaking for $10 \mathrm{~min}$, the aqueous phase was subjected to the Amberlite CG-120 column chromatography and eluted with $2 \mathrm{~N} \mathrm{NH}_{4} \mathrm{OH}$ solution. Through these procedures, acetylcarnitine was separated as

Received for publication, March 25, 1975. 
TABLE 1. Recovery rates of added carnitine and its esters

\begin{tabular}{lcc}
\hline Sample added & Number of experiment & Recovery rate (\%) \\
\hline Carnitine & 10 & $97.3 \pm 2.8$ \\
Acetylcarnitine & 10 & $94.1 \pm \mathbf{2 . 3}$ \\
Palmitoylcarnitine & 10 & $\mathbf{9 5 . 7 \pm 2 . 1}$ \\
\hline
\end{tabular}

free carnitine. The butanol phase containing palmitoylezrnitine was taken to dryness and the residue was hydrolyzed by heating in $6 \mathrm{~N}$ methanolic $\mathrm{HCl}$. Then, with the help of the butanol-water separation procedure and the column chromatography as described above, palmitoylcarnitine was obtained as free carnitine. Subsequent procedures for the assay of carnitine were performed by a modification of Friedman (Friedman 1958). The mean recovery rates of added carnitines were shown in Table 1. Repeated assays did not vary by more than $5 \%$. In this method co-existence of other choline-compounds and amino acids gave no serious effect on the assay.

The procedures were applied to determine the contents of carnitine and its esters in serum. Serum was mixed with 10 volumes of chloroform-methanol $(2: 1, v / v)$. The mixture was shaken vigorously for $10 \mathrm{~min}$ and filtered. After washing the residue twice with small amounts of chloroform-methanol, the pooled extract was evaporated to dryness. The residue was dissolved in $10 \mathrm{ml}$ of $n$-butanol, to which equal volume of distilled water was added. Serum carnitines were then treated and separated as described above.

Serum free carnitine contents in 125 healthy men and women ranged from 4.3 to 8.5 $\mu$ moles $/ 100 \mathrm{ml}$, with the mean of $6.4 \pm 1.3 \mu$ moles $/ 100 \mathrm{ml}$. Carnitine content varied slightly from day to day in the same subject and increased highly in fasting and in other states with increased lipolysis, in which the variation of the serum content paralleled with those of urinary excretion of carnitine (unpublished data). Carnitine esters, however, could not be detected in serum, even when as much as $100 \mathrm{ml}$ of serum were used to detect the esters. There was no change in carnitine content in serum which was allowed to stand at room temperature for up to $48 \mathrm{hr}$. The storage of serum at $-20^{\circ} \mathrm{C}$ for half a year had no effect on the content. This method may be applied to various types of study of carnitine metabolism.

\section{Aknowledgment}

We are grateful to Tanabe Seiyaku Co. for generous supply of synthetic carnitines.

\section{References}

1) Bøhmer, T., Norum, K.R. \& Bremer, J. (1966) The relative amounts of long-chain acylcarnitine, and free carnitine in organs of rats in different nutritional states and with alloxan diabetes. Biochim. biophys. Acta (Amst.), 125, 244-251.

2) Friedman, S. (1958) Determination of carnitine in biological materials. Arch. Biochem. Biophys., 75, 24-30.

3) Gumpen, S.A. \& Norum, K.R. (1973) The relative amounts of long-chain acylcarnitines, short-chain acylcarnitines and camitine in heart, liver and brown adipose tissue from rats fed on rapeseed oil. Biochim. biophys. Acta (Amst.), 316, 48-55.

4) Lindstedt, G. \& Lindstedt, S. (1965) The separation of carnitine from related compounds by ion-exchange and thin-layer chromatography. In: Recent Research on Carnitine, edited by G. Wolf, The M.I.T. Press, pp. 11-21.

5) Maebashi, M., Kawamura, N. \& Yoshinaga, K. (1974) Urinary excretion of carnitine in progressive muscular dystrophy. Nature, 249, 173-174.

6) Marquis, N.R. \& Fritz, I.B. (1965) The distribution of carnitine, acetylcarnitine and acetyltransferase in rat tissues. J. biol. Chem., 240, 2193-2196.

7) Mehlman, M.A. \& Therriault, D.G. (1965) Quantitative method for extraction and separation of free and lipid-bound carnitine. In: Recent Research on Carnitine, edited by G. Wolf, The M.I.T. Press, pp. 35-43. 